\title{
Restructuring Macroeconomic Policy for Sustainable Development in Nigeria
}

\author{
John Onuwa Okoh \\ http://dx.doi./org/10.4314/ujah.v21i3.16
}

\section{Abstract}

This paper examined the impact of restructuring macroeconomic policy for sustainable development in Nigeria. The paper examines the various efforts aimed at restructuring macroeconomics policy in Nigeria. These efforts were captured in the SAP of 1986, NEEDS of 2004, the Transformation Agenda of 2011 and the ERGP of 2016. The paper adopted content analysis method of qualitative research given the peculiarity of the subject matter. There were documented evidence that during the aforementioned periods, the economy showed signs of growth and development. Despite the gains of the reforms, Nigeria is still grappling with economic growth and development issues-unemployment, poverty and rising cost of living. This paper however recommends that there should be continuity in programmes and policies of government. Programmes and policies should not change with regime change. There should be a deliberate and conscious effort on the part of government and policy makers to design programmes and policies that are people oriented, home grown and have the capacity to promote and sustainable growth and development.

\section{Introduction}

The goal of government is to attain persistent increases in economic growth rates and sustainable development. Nigeria like most developing countries are often engulfed by economic growth and development issues, which generally include but not limited to rising poverty levels, unemployment, inflation, death to basic infrastructures etc. These issues have devastating consequences for sustainable 
development. The aim of any government therefore is to achieve and sustain accelerated growth and development of the economy (Okoh, 2017). This can be achieved via the restructuring and reformation of existing macroeconomic.

Restructuring macroeconomic policies basically can be considered as the adjustments made by governments and economic manager to ensure that important macroeconomic goals are attained so as to transforming the economy for sustainable development. According to Iyoha (2004), "The ubiquitous nature of macroeconomics in the life of every citizen in both the industrialized and developing countries is not difficult to establish. The joys, sorrows, and welfare of the citizenry in any modern country depend critically on the state of the macro-economy and on the policies of the government." This assertion can be seen in the area of inflation as in the sphere of unemployment, in the area of economic growth, in the area of taxation, balance of payments, tariffs, import quotas, and the exchange rate. As stated earlier, the goals towards which macroeconomic policy are directed includes: full employment (in practice, the reduction of unemployment to a minimum), full potential output (i.e. full utilization of all non-labour resources and reduction of excess capacity to minimum), rapid economic growth over-time (in order to ensure inter alia, a rising standard of living and increasing per capita income, for its citizen. All these gravitate towards the attainment of sustainable development in Nigeria.

In order to attain the aforementioned goals, the following tools are employed. Namely: fiscal policy and monetary policy. Others include commercial or trade policy, income policy, exchange rate policy and debt management policies etc.

In Nigeria, several attempts have been made to reposition the economy towards attaining sustainable development by ensuring structural changes. The structural Adjustment Program (SAP) of 1986 whose main objective was among others to diversify the productive 
base of Nigeria's economy, sought to achieve full potential output (i.e. full utilization of all non-labour resources). The National Economic Empowering Development Strategy (NEEDS) which was later implemented as a reform program by the Federal Government of Nigeria in 2004 was to achieve some macroeconomic goals of stability poverty alleviation wealth creation and employment generation (Adogamhe, 2007). The Transformation Agenda of 2011 among other objectives sought to lay the foundation for a robust and inclusive growth as well as improving on a sustainable basis the wellbeing of all classes of Nigerians regardless of their personal circumstances. (Okoh, 2018). The Economic and Recovery and Growth Plan (ERGP) of the Muhammadu Buhari led Federal Government is one of sustained inclusive growth. There is an urgent need as a nation to drive a structural economic transformation with emphasis on improving both public and private sector efficiency. This is aimed at increasing national productivity and achieving sustainable diversification of production to significantly grow the economy and achieve maximum welfare for citizens beginning with food, energy and security. The plan also recognizes the need to leverage Science Technology and Innovation (STI) and build a knowledge-based economy. The ERGP is also consistent with the aspirations of the Sustainable Development Goals (SDGs) given that the initiatives address its three dimensions of economic, social and environmental sustainability issues. (National Planning Commission 2017). This objective of the paper therefore is to examine the implications of restructuring economic policies for sustainable development.

\section{Literature Review}

Sustainable Development can be interpreted in economic terms as "development that lasts." It is a path along which the maximization of human well-being for today's generations does not lead to declines in future well-being. (Pearce \& Barbier, 2000). For the purpose of this 
paper, human well-being is interpreted as including not only the satisfaction of economic needs, but also aspirations for a clean and healthy environment and preferences in terms of social development. Macroeconomic policy restructuring is a drastic or fundamental change that alters the relationship between broad macroeconomic aggregates for the purpose enhancing sustained economic growth and development.

As noted earlier, the SAP of 1986, NEEDS of 2004, Transformation Agenda of 2011 and the ERGP of 2017 were attempts by Nigeria's economic manages as well policy makers to restructure macroeconomic policy framework of the nation. For the purpose of this paper, we shall examine these attempts in some details.

\section{Empirical Literature Review}

The National Economic Empowerment and Development Strategy was meant to be Nigeria's plan for prosperity. The government's ways of letting the people know how it plans to overcome the deep and pervasive obstacles to progress that the government and the people have identified at the time. To establish NEEDS a dedicated team took three years and travelled across the country, holding meetings and workshops to identify what the Nigerian people want for the future, what problems they face, and what can be done to overcome them. NEEDS was designed as the people's plan. It is up to regular Nigerians as well as the government to see that it is implemented. According to the National Planning Commission (2004) NEEDS emphasized the critical importance of improving infrastructure; more reliable electricity and a new and better maintained network of roads will encourage businesses to expand. NEEDS gives special support to agriculture, industry, small and medium-scale enterprises, and oil and gas. Under the plan, the government will seek long-term capital for investment. Trade policy, so critical to Nigeria's stake in the regional economy, will be 
modified to unburden business of the red tape and complex procedures that hinder it from flourishing. NEEDS envisages forging stronger links between educational institutions and industry to stimulate rapid industrial growth and efficient exploitation of resources. The visions and principles of NEEDS are represented in the diagram below.

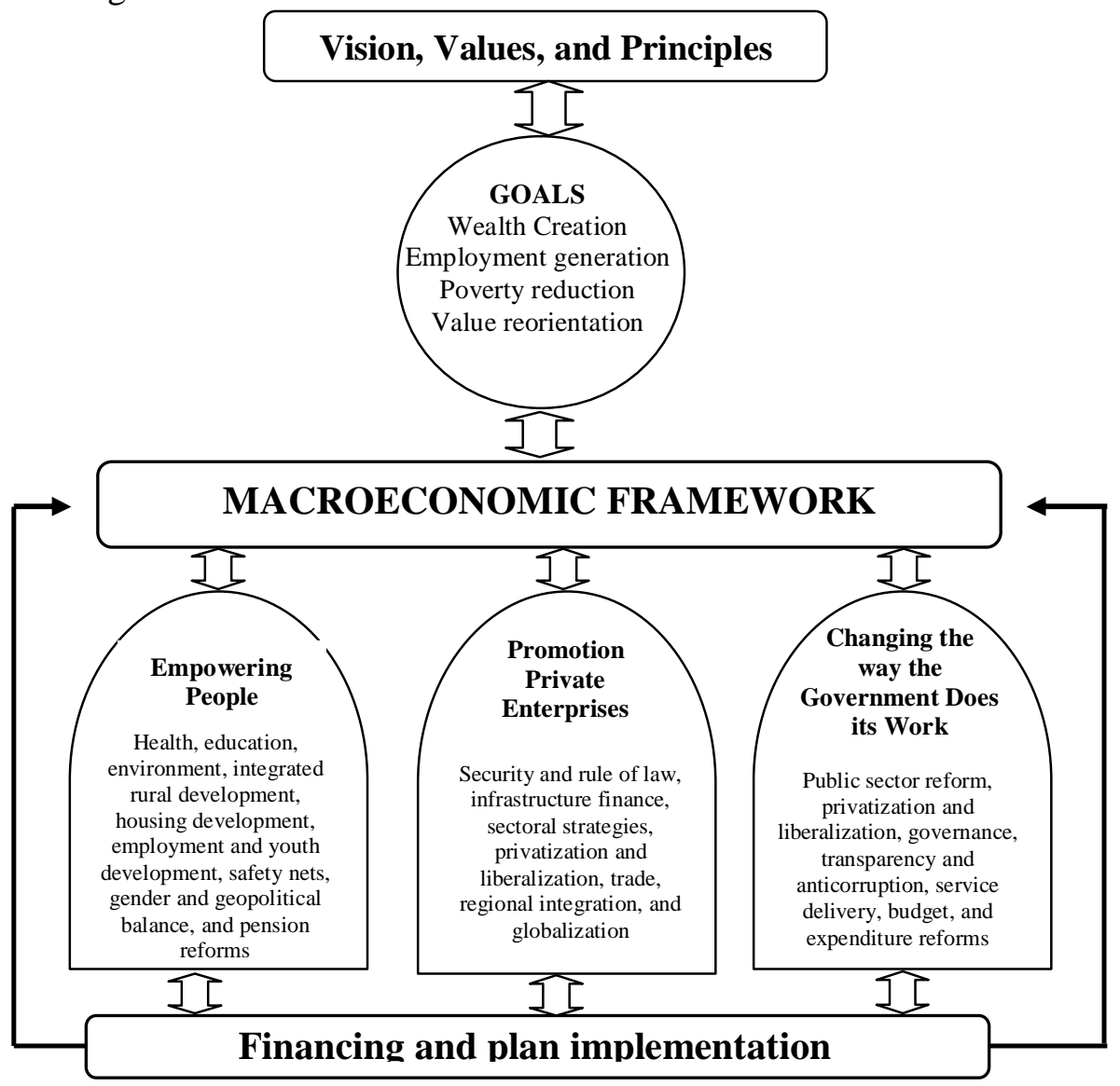

Fig. 1: Needs at a glance (Source: NEEDS Document 2004) 


\section{Macroeconomic Framework}

According to the National Planning Commission (2004), NEEDS is orientated towards three main objectives:

\section{(a) Empowering people}

By allowing the private sector to thrive, NEEDS creates opportunities for employment and wealth creation. It empowers people to take advantage of these opportunities by creating a system of incentives that reward hard work and punish corruption, by investing in education, and by providing special programmes for the most vulnerable members of society.

\section{(b) Promoting private enterprise}

The private sector will be the engine of economic growth under NEEDS. It will be the executor, investor, and manager of businesses. The government will play the role of enabler, facilitator, and regulator, helping the private sector grow, create jobs, and generate wealth. Deregulation and liberalization will diminish governmental control and attract private sector investment.

\section{(c) Changing the way the government does its work}

NEEDS aims to restructure the government to make it smaller, stronger, better skilled, and more efficient at delivering essential services. It seeks to transform the government from a haven of corruption to an institution that spurs development and serves the people. The number of government jobs will decline, and the cost of running the government will fall dramatically, as in-kind benefits for civil servants, such as subsidized housing, transport, and utilities, are monetized. Reforms and regulations will be implemented to ensure greater transparency and accountability, and corrupt practices will be outlawed. Government activities and budgeting will be informed by a 
framework that connects policy with government income and expenditure.

\section{(Ii) Plan Implementation Strategies}

\section{(a) New Forms of Coordination and Partnership}

NEEDS envisions several new forms of coordination and partnership, from matching grants to a peer review mechanism and public private partnerships. An ad hoc committee will be set up to take a census of federal government projects in the states and determine which can be passed on to communities, local governments, or states or sold outright. This committee will also identify the areas for direct intervention by the federal government and areas for facilitation or coordination and application of matching grants. Coordination among the tiers of government is important to avoid duplication and waste in the delivery of services. Under a proposed financing scheme, the federal government would provide matching grants to states and local governments for programmes that are national priorities but are best handled at the state or local level.

\section{(b) Peer Review Mechanism and Public-Private Partnerships}

A peer review mechanism was meant to be used at all levels of implementation within ministries and agencies; among ministries and agencies at the federal and state levels; at the federal, state, and local government levels; between the public sector on the one hand and the private sector and civil society organizations on the other; and within the framework of aid coordination. NEEDS also intends to mainstream public-private partnership at all levels of government for interaction with private sector associations, NGOs, and civil society organizations. 


\section{(c) Restructuring the National Statistical System}

NEEDS recognizes that Nigeria's national statistical system is weak. The current system is governed by the 1957 Statistics Act, which is obsolete. Timely and reliable statistics are critical to effective planning, monitoring, and evaluation. A new master plan has been developed for the national statistics system, and the government has increased funding for the Federal Office of Statistics.

\section{(iii) Financing the Plan}

NEEDS targets minimum annual GDP growth rates of 5 percent in 2004, 6 percent in 2005 and 2006, and 7 percent in 2007 (National Planning Commission 2004). While ambitious, it is the minimum needed to achieve adequate per capita income and improve welfare. To finance the program, the government will increase the efficiency of resource use by curbing wasteful expenditures (by plugging all leakages in public expenditure and sources of revenue and reforming institutions), selling assets, reforming the tax system, increasing the efficiency of resource use, mobilizing domestic savings, and attracting foreign direct investment and overseas development assistance. It will also seek debt relief from creditors.

Generally, the purpose of NEEDS is to raise the country's standard of living through a variety of reforms, including macroeconomic stability, deregulation, liberalization, privatization, transparency, and accountability, NEEDS tries to address basic deficiencies, such as the lack of fresh water for household use, and irrigation, unreliable power supply, decaying infrastructure, impediments to private enterprises and corruption. It is the hope of the government that NEEDS will create seven (7) million new jobs, diversify the economy, boost non-energy exports, increase industrial capacity utilization and improve agricultural productivity. A related initiative on the state level is the State Economic Empowerment and Development Strategy (SEEDS) and the local level (LEEDS). Also 
included in the agenda of this programme are the Human Development Agenda and social Charter, Integrated Rural Development, Housing Development, Health and Youth Development, as well as geographical balance, (Federal Government of Nigeria Official Gazette 2003).

The Transformation Agenda is a medium term, development strategy to speed up Nigeria's march towards becoming one of the twenty largest economies by the year 2020.It was derived from the Nigeria Vision 20:2020 (NV 20:2020) which is an articulation of the long term plan to launch Nigeria onto a path of sustained social and economic progress and accelerate the emergence of a truly prosperous and united nation. It serves as a frame work for the actualization of the Federal Government's economic growth agenda from 2011-2015 (National Planning Commission 2011). It was developed to consolidate the gains of the reforms of the last decade and is anchored on the pillars and specific targets of the Nigeria Vision 20:2020(NV: 2020). Thus as a road map for securing a better future, The Transformation Agenda is targeted at:

a. Creating decent jobs in sufficient quantities to address the protracted problem of unemployment and reduced poverty.

b. Laying the foundation for a robust and inclusive growth of the Nigerian economy; and

c. Improving on a sustainable basis, the well- being of all classes of Nigerians regardless of their personal circumstance.

Recognizing the enormous human and natural endowments of the country, the blue print is Nigeria's roadmap to improve the living standard of its citizens and place the country among the top 20 economies in the world by 2020, with a minimum GDP of $\$ 900$ billion and a per capita income of less than $\$ 4000$ per annum. The Pillars of the Transformation Agenda are summarized in figure 2 below: 


\section{The Transformation Agenda}

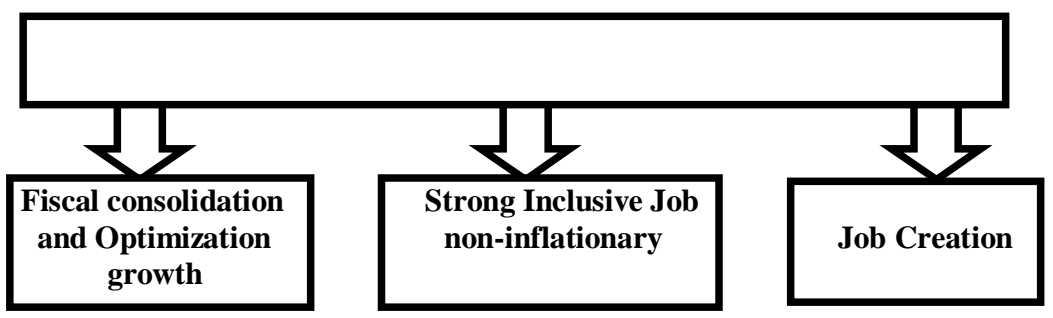

Figure 2: Pillars of the Transformation Agenda Source: NPC, The Transformation Agenda, 2011.

The Muhammadu Buhari led Federal Government designed the Economic recovery and Growth Plan (ERGP 2017-2020). It is a medium term plan which builds on the Strategic Implementation Plan (SIP) for the 2016 Budget of Change. The ERGP was developed for the purpose of restoring economic growth while leveraging on the ingenuity and resilience of the Nigeria people. The nation's most priceless assets. It is articulated with the understanding that the role of government in the $21^{\text {st }}$ century must evolve from that of being an omnibus provider of citizen's needs into a force for eliminating the bottlenecks that impede innovation and market based solution. The plan also recognizes the need to leverage Science Technology and Innovation (STI) and build a knowledge-based economy. The ERGP is also consistent with the aspirations of the sustainable Development Goals (SDGs) given that the initiatives address its three dimensions of economic, social and environment sustainability issues. (National Planning Commission, 2017).

The vision of the ERGP is one of sustained inclusive growth. There is an urgent need as a nation to drive a structural economic transformation with an emphasis on improving both public and private sector efficiency. This is aimed at increasing national productivity and achieving sustainable diversification of production to 
significantly grow the economy and achieve maximum welfare for the citizens, beginning with food, energy and security. The plan is a pointer to the type of Nigeria that people desire in the short to medium term and encourages the use of science, technology and innovation to drive growth. It also provides a blueprint for the type of foundation that needs to be laid for future generations and focuses on building the country into the future (Federal Government, Gazzette, 2017).

Several principles have driven the thinking and development of this plan. They include:

i. Focus on tackling constraints to growth

ii. Leverage the power of the private sector

iii. Promote national cohesion and social inclusion

iv. Allow markets to function

v. Uphold core values

The ERGP has three broad strategic that will help achieve the vision of inclusive growth outlined as stated in fig 3 below:

1. Restoring growth

2. Investing in our people and

3. Building a globally competitive economy.

\section{RESTORING GROWTH}

- Macroeconomic stability

- Economic diversification

-Fiscal stimulus

-Monetary stability

- Improving external BOT

- Energy

- Transportation

-Focusing on MSME

\section{E. R. G . P}

Investing in our people

- Social inclusion

- Job Creation and

Employment

-Improved Human Capital
GROWING A GLOBALLY COMPETITIVE ECONOMY

- Investing in infrastructure

- Improving the business environment

-Promoting Digibulded growth -Focusing on MSME 
Fig 3: Source: Author's design 2018.

By 2020, Nigeria will have made significant progress towards achieving structural economic change and having a more diversified and inclusive economy. (National Planning Commission 2017) overall, the plan is expected to deliver on the following key outcomes.

Stable Macroeconomic Environment: The inflation rate is projected to trend downwards from the current level of almost 19 percent to single digits in 2020. It also projected that the exchange rate will stabilize as monetary, fiscal and trade policies are fully aligned. This outcome will be achieved through polices that seek to remove uncertainty in the exchange rate and restore investor's confidence in the market.

Restoration of Growth: Real GDP is projected to grow by 4.6 percent on average over the plan period, from an estimated contraction of 1.54 percent recorded in 2016. Real GDP growth is projected to improve significantly to 2.19 percent in 2017, reaching 7 percent of the plan period in 2020. The strong recovery and expansion of crude oil and natural gas production will result as challenges in the oil producing areas are overcome and investment in the sector increases. Crude oil output is forecast to rise from about $1.8 \mathrm{mbp}$ in 2016 to $2.2 \mathrm{mbpd}$ in 2017 and $2.5 \mathrm{mbpd}$ by 2020 . Relentless his focus on electricity and gas will drive growth and expansion in all other sectors.

Agricultural Transformation and Security: Agriculture will continue to be a stable driver of GDP growth, with an average growth rate of 6.9 percent over the plan period. The Agricultural sector will boost growth by expanding crop production and the fisheries, livestock and forestry sub-sectors as well as developing the value chain. Investment in agriculture will drive food security by achieving 
self-sufficiency in tomato paste (in 2017) rice (in 2018) and Wheat (in 2020). Thus, by 2020, Nigeria is projected to become a net exporter of key agricultural products, such as rice, cashew nuts, groundnuts, cassava and vegetable oil.

Power and Petroleum Products Sufficiency: The ERGP aims to achieve 10GW of operational capacity by 2020 and to improve the energy mix, including through greater use of renewable energy. The country is projected to become a net exporter of returned petroleum products by 2020 .

Improved Stock of Transportation Infrastructure: By placing transportation infrastructure as one of its key execution priorities, effective implementation of this plan is projected to significantly improve the transportation network (road, rail and port) in Nigeria by 2020.

Industrialized Economy: Strong recovery and growth in manufacturing, SMES and service sectors are also anticipated particularly in agro-processing, and food and beverage manufacturing. Overall, the ERGP estimates an average annual growth of 8.5 percent in manufacturing rising from -5.8 percent in 2016 to 10.6 percent by 2020 .

Job Creation and Youth Empowerment: The implementation of the plan is projected to reduce unemployment from 13.9 cent at of Q3 2016 to 11.23 percent by 2020 . This translates to the creation of ever 15 million jobs during the plan horizon or an average of 3.7 million jobs per annum.

Improved Foreign Exchange Inflows: The reduction in the importation of petroleum products resulting from improvement in 
local refining capacity following the implementation of the ERGP is projected to reduce demand for foreign. The economic diversification focus of the plan is also projected to translate into enhanced inflows of foreign exchange from non oil sector. On the whole, Nigeria is expected to witness stability in exchange rate and the entire macroeconomic environment. The country should also witness a major improvement in economic performance which should result in the following amongst others:

(a) Reduction in importation of food items and refined petroleum products

(b) Improved power supply

(c) Higher quality transport infrastructure

(d) Expansion in the level of industrial production

(e) Reduction in poverty

(f) Greater inclusiveness in the spread of the benefits of economic growth.

\section{Methodology}

This paper adopted content analysis of library and textual material method of qualitative research. This method is suitable given the nature of the subject matter-restructuring, content analysis of library and textual materials method has become a popular technique within the social sciences. This flexibility and adaptability as regards changes in the research environment and can be conducted with minimal cost. However, researchers using this method have to use caution with these methods to ensure that they do not influence and do not bring undue personal bias to their interpretation of the findings (Ojo, 2012). 


\section{Evidence of Restructuring Macroeconomic Policy for Sustainable Development in Nigeria}

Monye-Emina and Odejimi (2007) conducted a study on trade policy reform between the period of 1970 and 2003. The variables of the model are Human Capital, Balance of Payment and National resources dependence. They employed the OLS and DF/ADF methods to examine the impact of the reform of the country's trade policies on its economic growth and its structure. The estimated coefficients indicate the Balance of Payment (BOP), Human Capital Development (H CD), were positive and statistically significant. National resources dependence, though positive, passed the test at 5\% significance level. Inflation failed the significance test, it did not pass event at $10 \%$.

Omitogun and Ayinla (2007) examined empirically the contribution of fiscal policy in the achievement of sustainable economic growth in Nigeria. Using the Solow growth model estimated with the use of Ordinary Least Square method, they found that fiscal policy has not been effective in the area of promoting sustainable economic growth in Nigeria. The variables of the model includes; exchange rate, interest rate, government expenditure and government revenue. Although, the finding seems invalidating the Keynesian postulation of the need for an active policy to stimulate economic activities, however, factors such as policy inconsistencies, high level of corruption, wasteful spending, poor policy implementation and lack of feedback mechanism for implemented policies evident in Nigeria which, are indeed capable of hampering the effectiveness of fiscal policy have made it impossible to come up with such a conclusion. To put the Nigerian economy, therefore, along the path of sustainable growth and development, the government must put a stop to the incessant unproductive foreign borrowing, wasteful spending and uncontrolled money supply and 
embark upon specific policies aimed at achieving increased and sustainable productivity in all sectors of the economy.

Appah and Ogbonna (2011) examined the impact of tax reforms on the growth of the Nigerian economy from $1994-2009$. To achieve the objective of the study, the study specified a model that consist of GDP, VAT, PPT, Education Tax, PIT, CIT and Customs and Excise Duty. Data were collected from the Central Bank of Nigeria, (CBN) statistical bulletin, Federal Inland Revenue Services (FIRS), and office of the Accountant General. The data collected were analysed using descriptive statistics and econometric models such as White test, Ramsey RESET test, Breusch Godfrey test, Jacque Berra test, Augmented Dickey fuller test, Johansen test and Granger causality test. The results from the various test shows that tax reform is positively and significantly related to economic growth and that tax reforms Granger causes economic growth. The study concluded that tax reforms improve the revenue generating mechanism of government to undertake socially desirable expenditure that will translate to economic growth. However, it was recommended that sustainable economic growth cannot be attained with tax reform processes except obsolete tax laws and rates are reviewed in line with macroeconomic objectives, corrupt-free and efficient tax administrative machinery with personnel and accountability and transparency of government officials in the management of tax.

Abdu (2011) investigates the extent to which the goal of poverty reduction has been achieved after the first phase of the implementation of NEEDS (2004-2007).The paper adopted the content analysis of library materials, publications and other documented researches pertaining to the subject-matter. The paper concludes that NEEDS has not made a significant impact on Nigeria's infrastructures and standard of living of the majority and, therefore, status of poverty remain at an alarming rate. The failure of NEEDS to significantly generate employment and reduce poverty has been 
attributed largely to weak institutional frameworks and lack of political will in the Nigerian state. To achieve poverty reduction and economic progress in Nigeria, majority of Nigerians must have access to quality education and the leadership must be truly committed to the economic reform agenda by encouraging development of stronger State institutions and creating an enabling investment environment.

Ogbonna (2012) examined the impact of Structural Adjustment Programme (SAP) on the Nigerian economy. The study was bifurcated into pre-SAP (1960-1985) and during SAP (19862008) to enable the investigation of how SAP achieved the cardinal objectives of exchange rate stability, minimal price escalation and trade balance adjustment. The variables of the model are exchange rate, trade balance and consumer price index. Using quarterly data for the period 1960-2008, the study employed a co integration analysis and Error Correction Mechanism (ECM) technique to test if the objectives were achieved. The results suggest that in the two periods under review, the role of exchange rate depreciation in trade balance adjustments appears to be inconsequential. The results further suggest that the problem of Nigeria appear not to be that of demand management as diagnosed by the prescribers of SAP, but rather that of supply. The exchange rate remained volatile and kept a downward trend while inflation and import index maintained rising profiles. All these suggest that SAP failed to achieve the cardinal objectives in terms of exchange rate stabilization, minimum acceptable inflation rate, substantial reduction in import demand index and non-oil export promotion. The study concluded that the CBN played its stabilizing role in the economy through reversed appropriate economic policies tailored towards effective supply management for improvised internal and external sector performance.

Opene and Odeh (2012), examined the relevance of NEEDs in the growth of the Nigerian economy from 1999 to 2010. Using time series data, they specified a model that consisted of the following 
variables-: Foreign Direct Investments (FDI), industrial output, exchange rate, inflation and population. The study adopted the ordinary least squares estimation techniques and the results showed that foreign direct investment exchange rate, industrial output and population exhibited a positive relationship with economic growth (proxy with real gross domestic product RGDP) and both FDI and population were statistically significant and explained about $79.2 \%$ and $81.6 \%$ respectively of the total variations in the RGDP. The study concluded that with the implementation of NEEDs, the economy witnessed an increased inflow of FDI (especially in aviation, telecoms and services sectors) and this brought about employment generation and wealth creation, hence the recommendation of increased inflow of FDI in other sectors of the economy as this will promote economic growth and create employment.

Gyong (2014), examined the Transformation Agenda as an economic reform programme to ascertain its impact on the growth of Nigeria's economy. He noted that a number of threats and challenges exists that hindered the realization of the Transformation Agenda. These according to him includes absence of good governance and accountability, ineffective public service, incessant problem of insecurity, corruption, bankrupt leadership, faulty development agenda that drove the Transformation Agenda. He concluded that there is need to take bold steps towards exploiting the maximum benefits of the opportunities of such reform policies while simultaneously reducing to the barest minimum, the threats and challenges facing it. Most importantly, some fundamental measures need to be taken in the thinking and actions of the leadership of the country. Also there is need for a radical development strategy that will guarantee inclusiveness as opposed to exclusiveness in the governance of the Transformation Agenda.

Oyewale and Ogunleye (2014) assessed the Impact of Transformation Agenda on Economic Performance in Nigeria. Using 
times series data, the study adopted SPSS 15.0 economic software for its regression analysis. The results showed that Nigeria achieved a modest macro-economic stabilization due to many reforms embarked upon by the government in the recent time with performance rates averaged between 3.5 percent and 7.0 percent. The study concluded that the Transformation Agenda impacted positively in Nigeria's economic growth. The study went further to recommend that for the Transformation Agenda to be meaningful, government must address the enormous challenges it faces in the areas of multiplicity of projects in the face of dwindling resources and the need to articulate a cohesive programme that is well focused and implementable so as to address the challenge of decay and inadequate infrastructure and growing unemployment, particularly of youths.

Ejike (2015) examined the impact of Economic Reform on the growth and development of the Nigerian economy. The scope was 1980-2015. He specified a model which was used in the evaluation of the impact of economic reform on the growth and development of the Nigerian economy. The variables in the model consists of Foreign Direct Investment (FDI), Investment, inflation, capacity utilization, exchange rate, human capital development and a dummy was used to capture reform. Using the ordinary least squares regression technique, he found that economic development increased by 16 percent during the reform period as compared to the non-reform periods. Economic growth increased by 4 percent during the reform as compared to the non-reform period, hence accepting the alternative hypothesis that there is a positive relation between economic reforms and economic growth and development.

\section{Conclusion/Recommendations}

The objective of this paper is to examine the effects of restructuring macroeconomic policy for sustainable development in Nigeria. The paper examined the various efforts aimed at restructuring 
macroeconomic policy in Nigeria. These efforts were captured in the SAP of 1986, NEEDS of 2004, the Transformation Agenda of 2011 and the ERGP of 2016. During the aforementioned periods, the economy showed signs of growth and development. Despite the gains of the reforms, Nigeria is still grappling with economic growth and development issues-unemployment, poverty and rising cost of living. This paper however recommends that there should be continuity in programmes and policies of government. Programmes and policies should not change with regime change. There should be a deliberate and conscious effort on the part of government and policy makers to design programmes policies that are people oriented, home grown and have the capacity to promote and sustain economic growth and development.

\section{John Onuwa Okoh}

Doctoral Student,

Department of Economics, Banking \& Finance Benson Idahosa University

Benin City, Edo State, Nigeria

johnokohjr@gmail.com

\section{References}

Abdu, J. B. (2011). National Economic Empowerment Development Strategy and Poverty Reduction in Nigeria: A Critique. Economics and Financial Review 1(1): 15-24.

Appah E. \& Ogbonna G.N (2011). Impact of Tax Reforms on Economic Growth in Nigeria. A Time Series Analysis. Journal of Social Sciences 4(1):62-68, 2012.ISSN:2041-3246

Ejike, C. (2015). The Impact of Economic Reforms on Economic Growth and Development in Nigeria1980-2015. (Unpublished Master's Dissertations), Delta state University, Abraka, Nigeria. 
Gyong, J.E (2014). "Transformation Agenda. A Social Analysis". European Scientific Journal. July edition vol. 8 No. 16 ISSN;1857-7881 (Print) e-1857-7431.

National Planning Commission, (2004). National Economic Empowerment and Development Strategy NEEDS. Abuja, Nigeria.

National Planning Commission, (2011). The Transformation Agenda. Abuja, Nigeria.

National Planning Commission, (2014). Economic Performance Under The Transformation Agenda. Abuja, Nigeria

National Planning Commission,( 2017). Economic Recovery and Growth Plan. Abuja, Nigeria .

Ogbonna, B.C. (2012). Structural Adjustment Programme (SAP) in Nigeria. An Empirical Assessment. Journal of Banking, Vol. 6, No 1, June 2012, 19-40:ISSN 1597-2569

Okoh, J.O (2017). Economic Reforms, Human Capital Development and Economic Growth in Nigeria. Journal of Arts and Social Sciences, College of Education. Agbor. Vol 1 No 1 January 2017.

Omitogun, O. \& Ayinla, T. A. (2007). Fiscal Policy and Nigerian Economic Growth. Journal of Research in National Development, 5(2).

Opene, S. \& Odeh, B.(2012). NEEDS and Economic Growth in Nigeria 1999 - 2010. Journal of Art and Social Sciences, School of Arts and Social Sciences. Federal College of Education Zaria, Nigeria 1 (2).

Oyewale I \& Ogunleye P (2014) “An Assessment of the Impact of the Transformation Agenda on Economic Performance in Nigeria, Interdisciplinary Journal of Contemporary Research In Business Vol. 4. No.11, March 2014. 